\title{
A real options and joint ventures perspective for strategic decision-making process in the case of dynamic industrial environments
}

\author{
Ana - Maria German ${ }^{1,}$, Flavius Aurelian Sârbu ${ }^{1}$, and Mircea Boşcoianu ${ }^{2}$ \\ ${ }^{1}$ Transilvania University, Department of Engineering and Industrial Management, Mihai Viteazul \\ Street, no. 5, Braşov, România \\ ${ }^{2}$ Henri Coandă Air Force Academy, Department of Fundamental Sciences and Management, Mihai \\ Viteazul Street, no. 160, Braşov, România
}

\begin{abstract}
Strategic decision - making process represents a challenge in a dynamic industrial environment. Nowadays, many instruments and techniques are used in the process of decision-making. The perspective regarding real options analysis (ROA), joint ventures (JVs) and strategic decision-making process (SDMP) is very important to be analyzed because it represents a key source to obtain competitive advantage in a turbulent environment characterized by competitiveness, dynamism and a proactive thinking. The aim of the paper is to offer an interesting framework that emphasizes the relationship between real options (ROs), JVs, transaction cost (TC), bargaining models (BM), agency theory (AT) and SDMP. Also, the paper analyzes a real case study and it suggests a business model that includes elements that conduce to an innovative management. The findings are very useful for decision-makers from organizations, researchers and students.
\end{abstract}

\section{Introduction}

The topic of uncertainty has received more and more attention in strategic management field and there has been interest in how industrial organizations might manage strategic decision - making under uncertainty. The aim of the paper is to provide a comprehensive and extension framework that emphasizes the relationship between real options (ROs), joint ventures (JVs), transaction cost (TC), bargaining models (BM), agency theory (AT) and strategic decision-making process (SDMP). In a dynamic industrial environment, the issues that are connected to the SDMP require a new thinking model. The goal of a new business model is to create and manage mechanisms that focus on the development of new opportunities by optimizing the existing knowledge, resources, capabilities and processes.

Additionally, the paper analyzes a real case study and it suggests a business model that includes elements that conduce to an innovative management. Based on the model proposed, the industrial organizations should reformulate their strategies and investors should develop new opportunities to gain competitive advantage and obtain performance.

*Corresponding author: german_ana_maria@yahoo.com 
The use of these instruments will help managers to take the right decisions in their organizations. Hence, strategic decision makers must understand how to preserve the opportunity to act in turbulent industrial environments. The framework and the model represent the first step in developing a paradigm for building the decision making process based on the existing resources, the development of the new opportunities and joint ventures, the agility in reconfiguring strategies based on combination of resources and capabilities in relation with the perspective offered by real option analysis.

\section{Real options analysis (ROA)}

An option is "the act of choosing, the power of choice, or the freedom of alternatives" [1]. A real option is "the investment in physical assets, human competence, and organizational capabilities that provide the opportunity to respond to future contingent events" [2]. ROA represents an important tool in strategic management for many reasons. Firstly, ROA offers unique and precious predictions on industrial organization' decisions for different types of strategic choices under uncertainty. In this case, industrial organizations can "unlock value at the joint venture termination stage and an important role exists for joint ventures that are transitional investments by design" [3]. ROA "emphasizes dynamic efficiency gains, downside risk reduction, and the organization's ability to seize upside opportunities over time by shifting value chain activities across borders in response to different uncertainties" [4]. Secondly, the theory emphasizes that maintaining flexibility under uncertainty has option value for many investments $[4,5]$. Thirdly, ROA offers a new perspective on organization' resource allocation processes by informing the strategic decision makers.

The critics of the literature suggest that RO are difficult to value with certainty and the methodology is complicated but Mun argues that " traditional approaches assume a statistic decision-making ability, while real options assume a dynamic series of future decisions where management has the flexibility to adapt given changes in the business environment" [6]. The volatility is often the variable that has the most important impact on the option value. As has been shown [7], there are three approaches to estimate the volatility: twin security information, Monte Carlo simulation and closed-form expression [8]. On one hand, ROA represents only an academic tool and it is not practical in the business and on the other hand ROA "ends up choosing the highest-risk projects as the higher the volatility, the higher the option value" [9].

If the uncertainty surrounding an investment is greater, the possibility that the option will be exercised, thus making its value higher is greater. In the literature, there are different types of options that influence the investment decisions: option to wait to invest, option to abandon, option to switch, option to contract (expand), option to grow, option to stage, call options, put options, timing options or portofolio of options. The real option to wait to invest indicates to wait until further information reduces the market uncertainty. The option to abandon refers to dispose of a project that is not profitable. The option to switch changes the input or the output parameters. The option to contract (expand) is influenced by the market conditions. The option to grow refers to the future opportunities and the option to stage breaks up the investment into conditional steps. [1]. A call option is "an option in which the buyer has the right, but not the obligation, to buy a specified quantity of a security at a specified price named strike price within a fixed period of time but until its expiration $[10,1]$. A put option is "an option in which the buyer has the right but not the obligation to sell a specified quantity of a security at a specified strike price within a fixed period of time but until its expiration $[10,1,11]$. Timing option can be used when there are "large investment projects that show a large probability of realizing a negative net present value" [12]. Portofolio options can be very useful for joint ventures (JV). RO valuation method of investment projects is the extension of the financial options theory on real 
property. The two known option calculators are Black \& Scholes option valuation model and the binomial option valuation model.

\section{Joint ventures (JV)}

JV are defined as "equity-based collaborative arrangements whereby two or more organizations each contribute resources, including equity, for the joint pursuit of economic goals" $[13,3]$. According to the ROA, JVs are "analogous to call options in the sense that they provide their partners the right (not the obligation) to buy the developed technology (underlying asset) at a specific price (exercise price) at or before a specific date (expiration date)" [14]. In addition, "JVs provide the industrial organization with the option to access certain technological capabilities, acting as a platform to profit from future technological opportunities while avoiding full resources commitment, i.e. maintaining flexibility" [14].

One of the advantages of ROA is that it offers a dynamic perspective which can explain the JV's stages, from formation to exercise [15]. The options embedded in JVs will have an impact on the distribution of the equity stakes because an investor who aims to capture the dynamic RO part will invest in a smaller share of the JV because this way (s)he limits the downside risk while preserving the opportunity to capture the upside potential [4]. The value of the dynamic option part represents "a function of the same five factors that determine the value of financial options," (the value of the underlying asset, the strike price, the time to maturity, the risk-free rate and the uncertainty surrounding the underlying asset). $[16,3]$. Hence, the value of the options fixed in JVs is connected to market, uncertainty and partner-related.

\section{Strategic decisions-making process (SDMP)}

Strategic decisions involve investments in technology and development activities that must contain resources to future benefits in a dynamic and uncertain environment. The strategic decision - making process required for investment management is correlated to the resource-based view and to its management. Resources are "the foundation for strategy and unique bundle of resources generate competitive advantage leading to wealth creation" [17]. The studies based on strategy and finance have suggested that ROA represents a powerful valuation tool as well as a "systematic strategy framework to evaluate and structure resource investments under uncertainty and that successful use of RO can lead to the benefits of downside risk reduction and upside potential enhancement" $[3,18,2]$. RO investment decisions involves the mapping investments to options, the timing investment and the structuring investment. The implementation of RO refers to the levels of analysis (i.e. managerial/organizational dimensions) and to the implementation stages (i.e. creation, evaluation, maintenance, exercise). The performance outcomes of ROA are observed in measures (e.g. traditional risk measures, Tobin`s Q etc.) and in customized measures (e.g. downside risk, economic exposures etc.) [3].

Alternative approaches that are connected to the decisions, including the distribution of JV equity shares, are transaction costs economics (TCE), the bargaining perspective (BP) and the agency theory (AT). TCE describes the organization as "an efficiency-inducing administrative instrument that facilitates exchange between economic actors" [19]. There are two assumptions underlying the TCE perspective. In the first assumption, "individuals within an organization are assumed to be boundedly rationale - they are limited in their ability to plan for the future and to accurately predict and plan for the various contingencies that may arise" - [19] and the second assumption refers to the opportunism - some economic actors are "self-interest seeking with guile" [20] or subject to "frailties of motive" 
[21]. The ownership distribution of a JV is "the outcome of negotiations in which relative power is a deciding factor because the partner's level of ownership to be positively is related to its advertising intensity, its provision of market access and the amount of technology that it contributes and to be negatively, it is related to its number of competitors" [3]. The ownership structure of industrial organizations influence agency costs. Agency theory relates to "situations in which one individual (called the agent) is engaged by another individual (called the principal) to act on his/her behalf based upon a designated schedule [22]. The AT "posits different organizational, behavioral, economical and controlling roles, and it is a useful framework which can be extricated in promulgation of the management control systems" [22].

\section{Project valuation using ROA (case study)}

Manufactories have to adapt to the dynamic business environment. The decision-making process should be based on combinations of options, resources and capabilities.

Problem:

An aeronautical manufactory, through a JV, decide to develop a new product to improve the performance of its airplanes. The present value underlying assets is 100 TEUR. Volatility of the logarithmic returns on the project future cash flows is $35 \%$ and the riskfree rate on a riskless asset for the next five years is $3 \%$.

Using real options super lattice software to take the best decision, the analyze follows some steps.

Step I. Determinate the underlying asset lattice

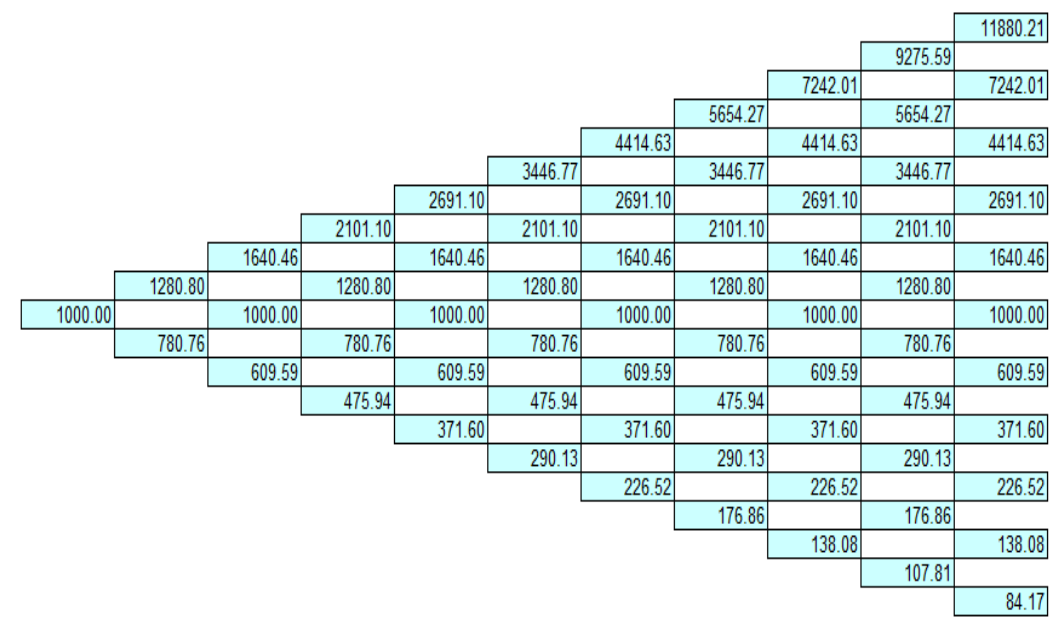

Fig. 1. Underlying asset lattice.

The figure represents the lattice evolution of the underlying with a volatility of $35 \%$. Using the binominal approach, is calculated the value of the contraction options following a ten time-steps. All the calculations and steps are based on the up factor, down factor and risk-neutral probability analysis. 
Step II. Determinate the sensitivity

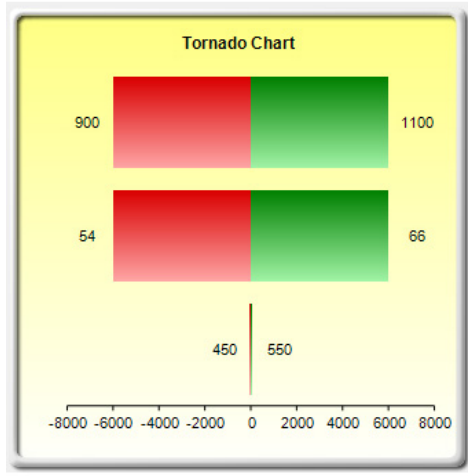

Fig. 2. Tornado Chart - determination of the sensitivity.

This analysis runs a quick static sensitivity of each input variable of the model at a time and lists the input variables with the high test impact to the lowest (according to real options super lattice software). The lattices result a good convergence. The figure represents the Tornado Chart with $35 \%$ volatility.

Step III. Simulation process

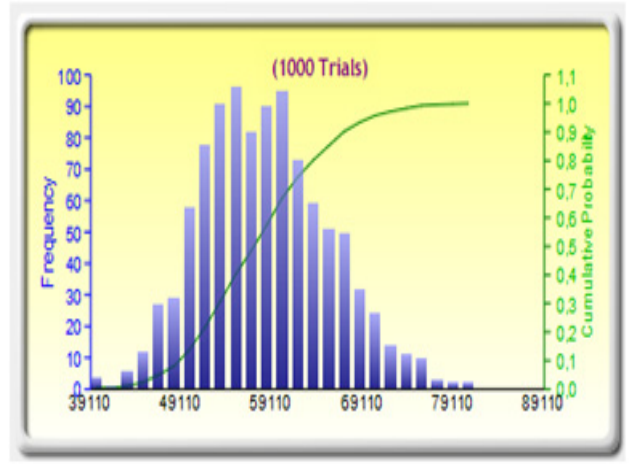

Fig. 3. Simulation process with volatility $35 \%$.

The figure represents the simulation of the option taking into account the present value, the implementation costs, the maturity, the risk - free rate and the volatility. The figure illustrates that at 1000 trials with volatility $35 \%$, the mean is $60.636,51$ the standard deviation is $8.447,16$ and the range is $50.814,05$.

Step IV. Creating a business model

The industrial management represents an important topic that should be taken into consideration. In this context, it is necessary to develop a model that could be used by enterprises to obtain competitive advantage and performance. 


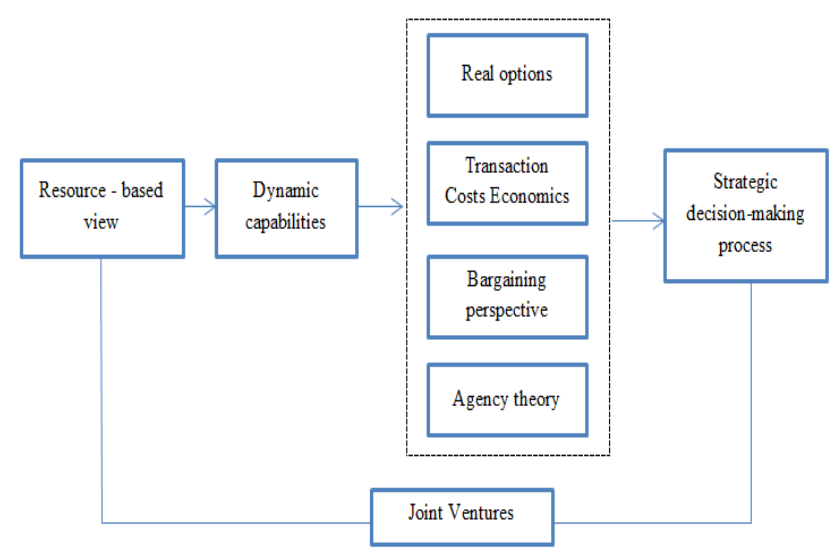

Fig. 4. Looking ahead: a general business model.

The model is focused on the resource-based view, dynamic capabilities, real options, transaction costs economics, bargaining perspective and agency theory. All this elements have a joint ventures foundation. The model emphasizes the importance of different tools in the process of elaborating the strategy. All this elements represent a source to gain competitive advantage and to obtain business performance.

It can be seen from the figures the importance of using ROA in high volatile environments and their role on protection against high uncertainty elements, especially in major investments decisions. The case study presented suggests that ROA can be used in decision-making managerial process for industrial organizations. The results obtained after the analysis suggest that it is a great choice to implement the project based on the development of a new product and the joint ventures.

\section{Conclusions}

In a turbulent business environment the technological progress is not sufficient. The analysis of the ways to obtain the performance of industrial organizations should be focused on the active selection of different variables/elements and on the mixing of different mechanisms that generate sustainable competitive advantage. The integration of ROs and $\mathrm{JVS}$ in the process of strategic decision - making, together with other paradigms that contain flexibility elements such as: TCE, BP, AT, represents an interesting instrument to gain competitive advantage. The way toward a better understanding of this elements conduce to performance, efficiency, effectiveness, competiveness and innovation.

The paper offers valuable information and provides for managers an integrative perspective of the ROA and JVs. The findings suggested in this paper show that real options and joint ventures can represent a source of competitive advantage for industrial corporations if they are put into practice by managers. By using ROA, industrial organizations can gain competitive advantage by choosing the optimal strategy. The value of strategic options is offered by variables and elements that are influenced by competition, demand and a good management. The case study presented is a strong proof that suggests that ROA should be used in industrial companies. The business model offered by the authors emphasizes precious elements such as: resource-based view, dynamic capabilities, real options, transaction costs economics, the bargaining perspective and agency theory. This elements represent the keys to an efficient decision - making process and to business performance. In addition, the framework, the case study and the business model represent a tool that is useful for managers but also, for student and researchers. 
Further studies will focus on the development of a hybrid model necessary to an efficient management and an assessment procedure of the model because knowledge brings innovation and innovation brings competitive advantage and performance.

\section{References}

1. M. Branch, Real options in practice (John Wiley \& Sons, Inc., Hoboken, New Jersey, 2004)

2. B. Kogut, N. Kulatilaka, Org. Scien. J. 12(6), 744-758 (2001)

3. J. Reuer, T. Tong, Real options Theory (Elsevier, U.K., 2007)

4. J. J. Reuer, How real are real options? The case of international joint ventures (Oxford Blackwell Publishing, 2002)

5. J.C. Hull, Options, futures, and other derivative securities (Prentice-Hall, 2003)

6. J. Mun, Real options analysis: Tools and techniques for valuing strategic investments and decisions (John Wiley \& Sons, Inc. USA, 2002)

7. L.T. Miller, C.S. Park, The Engin. Ec., 47(2), 105-150 (2002)

8. A.M. German, M. Boscoianu, Gaining competitive advantage in a global business environment - the case of SMEs in emerging markets (Strategica Int. Conf., Tritonic 2015)

9. H. B. Nembhard, M. Aktan, Real Options in Engineeing Design, Operations and Management (Taylor \& Francis Group CRC Press, 2010)

10. A. Sullivan, S. Sheffrin, M. Steven, Economics: Principles in action. Upper Saddle River (Pearson Prentice Hall, 2003)

11. N. Fernandes, Finance for Executives: A Practical Guide for Managers (NPV Publishing, 2014)

12. S. Orsag, Izvedenice, HUFA, Zagreb (2006)

13. X. Martin, R. Salomon, Organiz. Scien., 14(3), 297-311 (2003)

14. I. Estrada, G. Fuente, N. Martin-Cruz, Res. Policy, 39(9), 1185-1197 (2010)

15. I.R. Cuypers, X. Martin, Adv. in Strat. Mn., 24, 107-148 (2007)

16. A. Seth, S.M. Kim, Valuation of international joint ventures: A real options approach. (Quorum Books, 2001)

17. C. Brush, P. Greene, M. Hart, Acad. of Mn. Execut., 15(1), 64-78 (2001)

18. L. Trigeorgis, Real options: Managerial flexibility and strategy in resource allocation. (MIT Press, 1996)

19. M.J. Leiblein, J. Mn., 29(6) 937-960 (2003)

20. O.E. Williamson, Markets and hierarchies: Analysis and antitrust implications (New York, Free Press, 1975)

21. H. Simon, Models of bounded rationality: Behavioral economics and business organization (Cambridge, MA: MIT Press, 1982)

22. M. Namazi, J. of Accoun. and Taxat., 5(2), 38-47 (2013) 